\title{
Forest Disturbance Information Layer for Alpine Forest Habitats
}

\author{
Antonia OSBERGER and Dirk TIEDE \\ Interfaculty Department of Geoinformatics - Z_GIS, Salzburg/Austria · antonia.osberger@sbg.ac.at
}

This contribution was double-blind reviewed as extended abstract.

\section{Introduction}

The EU project MS.MONINA (Multi-scale Service for Monitoring NATURA 2000 Habitats of European Community Interest, www.ms-monina.eu) - a GMES project funded within the EU's Seventh Framework Programme (FP7) - is developing remote sensing based services to observe and manage the state of Natura 2000 sites and other precious habitats to reduce the loss of biodiversity. One objective of the project is the provision of ready-to-use information to public authorities on European, national and local level in a multi-scale approach. Within this context the information layer concept has been introduced to provide specific and standardized information as an intermediate product to support further analysis activities (e.g. expert based interpretations, input for habitat modelling activities, etc.). This study examines the potential for calculating such an information layer of forest disturbances based on satellite imagery of different time slices in alpine forest habitats.

\section{Information Layer Concept}

The idea and development of the information layer concept within the project MS.MONINA aims to harmonize information output. Specific image information (sensor independent if possible) is extracted and analysed to represent features relevant for the assessment of Natura 2000 habitats. The contents of the information layers are standardized in terms of information content (one feature or information class per layer) and format (GeoTiff or Shapefile). These layers are considered as an intermediate product for further mapping and monitoring initiatives, as input for habitat classification models or as final products for indicating habitats condition. The users are able to request and access the information layer for each service case via the internal MS.MONINA SDI.

\section{$3 \quad$ Study Site and Data Sets}

\subsection{Study site}

The study site is located in the southern part of the federal state of Upper Austria (see Fig. 1). This region comprises the whole Kalkalpen National Park where the forest is primarily allowed to develop naturally. The national park itself covers an area of 
$208.5 \mathrm{~km}^{2}$,'while the entire study area is about $920 \mathrm{~km}^{2}$. In the year 2004 the national park was declared as a European protected site in the network of Natura 2000, according to the European Birds (79/409/EEC) and Habitats Directive (92/43/EEC).

Forest stands represent $81 \%$ of the national park area. Beyond the national park commercial forests with concrete management tasks are located. In recent years especially the mountain spruce stands faced progressive infestation of spruce bark beetles (Ips typographus). This mainly arose from major storm events in conjunction with particularly hot and dry summers. Forest disturbances triggered by abiotic (storm) and biotic (insect pests) factors result in coarse woody debris. Forest authorities require the assessment of those areas and their changes over time.

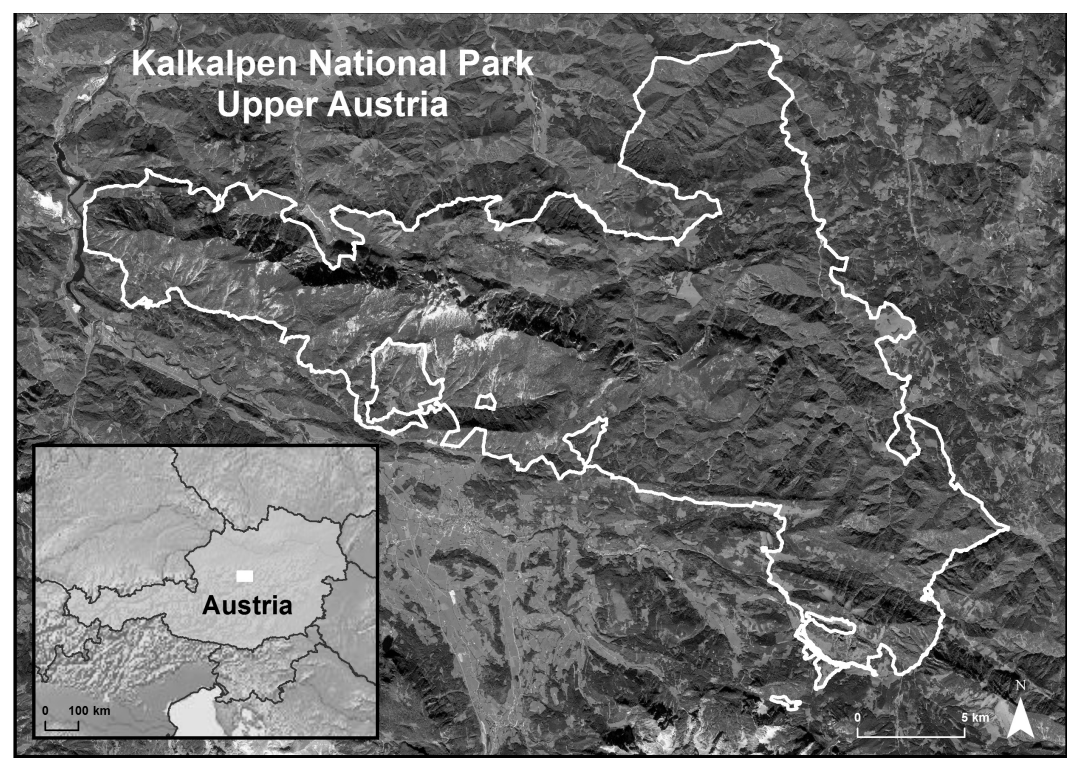

Fig. 1: Study site in Upper Austria, including the Kalkalpen National Park (outlined in white)

\subsection{Data}

For the change detection / forest disturbance analysis multispectral high resolution (up to 5 $\mathrm{m}$ ground sample distance) RapidEye images were used. One advantage of the RapidEye imagery is the ability of the sensor to detect subtle changes in vegetation health because of the availability of an additional red-edge band. The images are nearly cloud free and were taken in August 2010 (23.08.2010) and in September 2011 (11.09.2011).

The reference data to evaluate the generated forest disturbance layer are mapped dead wood areas (downed as well as standing dead trees) by the national park authorities. Most of the references are available as point information of the year 2011 complemented by some polygon features. 


\section{OBIA for Forest Disturbance Detection}

Data integration, data analyses and change indication were tackled by an object-based image analysis (OBIA, cf. BLASCHKE 2010; LANG 2008) approach. A rule-set for the forest disturbance information layer extraction, based on an automated change indication algorithm, was written in CNL (Cognition Network Language) within the Software eCognition Developer 8 (Trimble Geospatial). The rule-set focuses on the statistical interpretation of image objects to be more independent of different recording conditions and missing atmospheric corrections (transferability issue). It mainly uses the NDVI (Normalized Difference Vegetation Index) per image object, which has been normalized against the individual satellite images to indicate forest disturbances (small clouds are masked out). Three segmentation levels were used: (1) chessboard segmentation (regularly gridded layer) representing the information layer on the highest scale level. Results of lower scale levels were automatically aggregated to this level (reporting level); (2) Multiresolution segmentation (BAATZ \& SCHÄPE 2000) using the 2011 data only; (3) Multiresolution segmentation using the 2010 data only. Object-specific change indications between level 2 and 3 were aggregated to the highest reporting level and exported in the proposed information layer format. The aim of the information layer is in this case a fast and transferable indication of forest disturbances, focussing on a slim rule-set (concerning computational power) and only relative spectral thresholds for disturbance detection (increasing the transferability to other areas/images).

\section{$5 \quad$ Results and Discussion}

Forest disturbance indications are provided in regular $500 \times 500 \mathrm{~m}$ raster cells (see Fig. 2, left) to serve as an input for additional analysis/interpretations. Initial validation with the available reference data shows, that the pattern of the disturbance indication matches quite well the pattern of the reference data (see Fig. 2b).
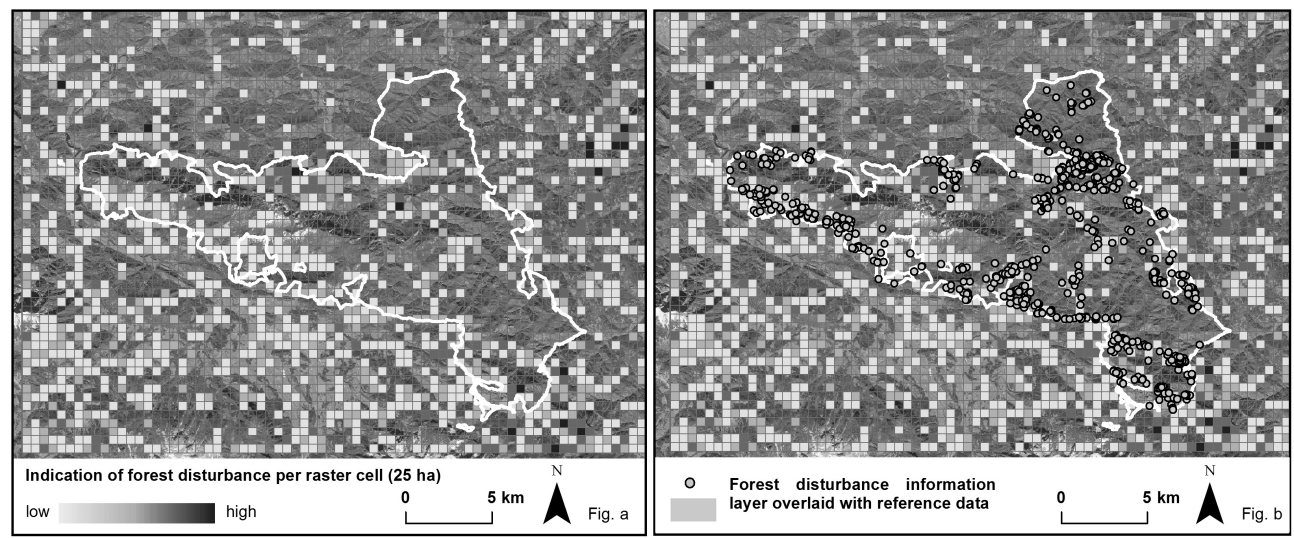

Fig. 2: Forest disturbance information layer for the southern part of Upper Austria, 2010 - 2011: Grid cells without disturbance indications are transparent (Fig. a) and overlain with the reference data for the national park region (Fig. b) 
To some degree even fine-scaled forest disturbance areas were detected. Problems are occurring especially in canyons and steep slopes of the national park region. This leads to an overestimation in comparison to the reference data. Besides of problems due to algorithmic or imagery reasons, also an underestimation within the reference data has to be taken into account. Some of these areas are very difficult to access or estimated from opposite hillsides only (personal communication with the national park authorities). In managed forest stands it is additionally possible that the approach detects clear cuttings. A detailed validation of the forest disturbance layer is still in process.

\section{Conclusion}

The fact that sustainability has become a main objective in nowadays forest ecosystem management has, as one of its consequences, the continuous need for timely, reliable and area-extensive resource data for monitoring purpose. The forest disturbance information layer is one idea to serve some of these requirements. It can quickly extract tangible information from remote sensing data to assess forest disturbances and related changes over time and can be used as information input into further analysis tasks. In order to investigate the transferability of the approach the concept will be transferred and evaluated with different sensors (HR, VHR, LIDAR data).

\section{Acknowledgements}

The work of Antonia Osberger is financed through a DOC-fFORTE-fellowship of the Austrian Academy of Sciences and carried out at the Interfaculty Department of Geoinformatics - Z_GIS, University of Salzburg. The authors would like to thank the Kalkalpen National Park GmbH, Upper Austria, Austria, for providing the imagery and insitu data used in this study as well as for the support in validation of results. The research leading to these results has received partly funding from the European Community's Seventh Framework Programme (FP7/2007-2013) under grant agreement No. 263479.

\section{References}

BAATZ, M. \& SCHÄPE, A. (2000), Multiresolution segmentation: an optimization approach for high quality multi-scale image segmentation. In: Proceedings of the 12th Symposium for Applied Geographic Information Processing (Angewandte Geographische Informationsverarbeitung XII. AGIT 2000), Salzburg, Austria, 12-23.

BLASCHKE, T. (2010), Object based image analysis for remote sensing. ISPRS International Journal of Photogrammetry and Remote Sensing, 65 (1), 2-16.

LANG, S. (2008), Object-based image analysis for remote sensing applications: Modelling reality - dealing with complexity. In: BlASCHKE, T., LANG, S. \& HAY, G. J. (Eds.), Object-Based Image Analysis - Spatial concepts for knowledge-driven remote sensing applications. Springer, Berlin, 3-27. 